\title{
Parenting Strategies to Deal with Children's Anxiety: Do Parents Do What They Say They Do?
}

\author{
Ana Beato $^{1}$ Ana Isabel Pereira ${ }^{1} \cdot$ Luísa Barros $^{1}$
}

Published online: 2 August 2016

(C) Springer Science+Business Media New York 2016

\begin{abstract}
Parents' perceptions about their strategies to deal with children's anxiety have been minimally explored. Based on a mixed-method approach, the current study compared the strategies that parents said they use more frequently to deal with their child's anxious behaviors and the strategies they actually used during two mildly anxiogenic interactions with their child. Forty-two parents of children with anxiety disorders, aged 9-12 years, participated in the study. Semi-structured interviews were administered to identify parental perceptions about their strategies to deal with their children's anxiety. Subsequently dyadic interactions were observed and coded by two independent coders. We found discrepancies relating to four strategies. Significantly more parents used strategies based on overinvolvement and anxious behavior during the interactions than had been reported by them in the interviews. In contrast, reassurance and reinforcement of avoidance/dependence were used in interactions by fewer parents than would be expected, according to the interviews. Relevant implications for assessment and intervention with families of anxious children are suggested.
\end{abstract}

Keywords Children anxiety · Strategies · Parenting · Multi-method · Discrepancies

Ana Beato

anabeato@campus.ul.pt

1 Faculty of Psychology, University of Lisbon, Alameda da Universidade, 1649-013 Lisbon, Portugal

\section{Introduction}

It has been repeatedly demonstrated that anxiety aggregates in families [1]. Nevertheless, the mechanisms of intergenerational transmission of anxiety, resulting from the interaction between genetic and environmental factors, remain unclear. Environmental components are considered to explain two-thirds of the variance of anxiety [2] and, among them, the role of parenting styles has been particularly highlighted [3, 4]. Theoretical models and research have emphasized two broad parenting dimensions-rejection and, particularly, overcontrol [e.g., 5-7]. The association between children's anxiety and these parenting dimensions was studied using both self-report and observational methodologies [see 8,9]. Parental overcontrol has been conceptualized as "a pattern of behavior involving excessive regulation of children's activities and/or routines, high levels of parental vigilance and intrusion, and the discouragement of independent problem-solving" and parental rejection as "parental hostility, indifference, noninvolvement and criticism" [10, p. 332].

Nevertheless, these global and non-anxiety specific parenting style dimensions seem to account for only a reduced proportion of children's anxiety [see 8]. Thus, research has been expanded to further study more detailed mechanisms of intergenerational transmission of anxiety. Contrasting with parenting styles, parenting 'practices' or 'behaviors' are conceptualized as specific parental interactions with children in specific situations, and are hypothesized to directly affect children's emotional and behavioral regulation [e.g., 11, 12]. Research has shown that parents of anxious children tend to give less autonomy [e.g., 13], model and reinforce avoidant behavior [e.g., 14, 15], convey more anxiogenic information [e.g., 16] and are less encouraging of bravery [17]. Furthermore, parents 
of anxious children have negative expectations about their children's ability to cope with anxiety, expecting more avoidant behaviors from them $[18,19]$. This may reinforce the child's sense of inefficiency to face difficulties and, as such, promote avoidance and dependence.

Given the bidirectional influence in parent-child relations, anxious children are also prone to elicit negative responses from their parents. Parental behaviors, such as over-control and reinforcement of the child's anxious behavior, are usually intended to reduce or eliminate the child's distress [7]. The adoption of this type of behavior may reflect parents' own distress and anxiety [20], which can be amplified when interacting with an anxious child [21]. In the short term, some of these maladaptive behaviors might seem effective in decreasing the child's distress. However, the repetition and generalization of this interactional dysfunctional cycle may have serious implications such as reinforcing children's anxiety and their perception of lack of control over the environment [22], decreasing children's sense of competence to cope with stressful situations and increasing withdrawal behavior and the difficulties of anxiety regulation [23]. Plus, recently Ginsburg et al. [24] have shown that changes in parental modeling, that is, the way parents exhibit their own distress in front of their children, is an important moderator for improvement and prevention of child anxiety in a high risk sample, which highlights the role of parental anxiety and distress in the maintenance and amelioration of children anxiety.

In the opposite direction, granting appropriate autonomy and encouraging children to face their difficulties are thought to promote a sense of mastery and control over the environment [22]. Previous research has shown that adaptive parenting behaviors, such as parental support or responsiveness, are positively associated with more adaptive childhood coping strategies, such as problem solving or seeking social support [25-27] and are inversely associated with ineffective strategies, such as avoidance [28, 29]. Positive rearing contexts are hypothesized to model and encourage effective strategies, as well as to increase the child's ability to cope with stressors [30]. Several studies showed that children who perceived their parents as critical and intrusive were more likely to use ineffective strategies, such as avoidance or distraction [31, 32].

Despite the noteworthy advances on the characterization of parenting factors associated with children's anxiety, important questions remain unanswered. Firstly, parental behaviors and strategies used to deal with and manage the child's distress are still greatly unspecified. Understanding how parents react to their child's anxious responses is crucial to promote the child's adjustment [33]. Secondly, the parental styles described above are usually assessed by independent raters or with questionnaires derived from theoretical models, failing to analyze parents' self- perceptions about their behaviors and strategies in everyday life. In a preliminary exploratory study, Hiebert-Murphy et al. [34] identified the strategies parents found more effective to deal with their child's anxiety. A range of parenting responses were mentioned (e.g., encouraging the child to face the situations, verbally comforting the child or reasoning with the child), although parents tended to be reactive and did not report a consistent use of these strategies. Characterizing these parental strategies and analyzing the consistency of their use in different contexts represents an important step towards a better comprehension of this issue. Thirdly, several studies identified significant inter-informant discrepancies regarding the evaluation of the child's anxiety, which might be due to various factors, such as the nature of anxiety symptoms (i.e., more or less observable), the setting (i.e., family or extra-family context) or the methods [e.g., 35]. Similarly, the use of different methods (e.g., self-report vs observed behaviors) and informants (e.g., parent vs independent observer) may also lead to discrepancies regarding the assessment of key parental behaviors in the context of children's anxiety [36]. Parents' lack of awareness of their own behavior, a social desirability effect or their own emotional state (e.g., calm vs distressed), seem probable reasons to anticipate such inconsistencies [37, 38]. Furthermore, few studies have explored the discrepancies within each informant. Finally, most studies about parenting and children's anxiety focus primarily on mothers, leaving the role of fathers unaccounted for [39, 40].

The current study intended to fill these gaps. Our main objectives were: (a) to explore which strategies parents report to use more frequently in daily life, when the child is distressed; (b) to explore which strategies parents use to deal with children's expressed distress during two moderately anxiety-provoking situations; (c) to identify possible discrepancies between self-reported and observed parental strategies.

Given the scarcity of research in this specific domain, no hypotheses can be drawn or tested. However, based on empirical and clinical knowledge, we may anticipate that most parents of anxious children will use strategies based on overinvolvement, reinforcement of anxiety and reinforcement of avoidance/dependence to deal with the child's anxiety. We also expect some discrepancies between the strategies identified by these two distinct methods (interview and observation).

\section{Method}

\section{Participants}

The sample consisted of 42 parents ( $n=23$ were mothers; $54.8 \%$ ) of 30 anxious children (50\% were boys) drawn 
from a larger study on children's anxiety and parenting. Children ranged from 9 to 12 years old $(M=10.10$; $S D=1.12$ ). Thirteen children had one sibling, 8 had two or more siblings and 9 were the only child in the family. Parents' ages ranged from 31 to $53 \quad(M=41.18$, $S D=5.01)$ years old. In terms of parent's educational level, $12(28.6 \%)$ had completed the 9th grade or less, 13 (31\%) had finished high school, $11(26.6 \%)$ had a college or university degree and $4(9.5 \%)$ had tertiary education. All participants were the biological parents of the children, except for one stepfather who lived with the child since she was born, and all were married or living in common-law marriage. The socioeconomic level was relatively welldistributed across families (28.6\% low; $45 \%$ medium; $21.4 \%$ high; $4.8 \%$ was impossible to determine). Some children had both parents participating in the study, while others only had one of them participating. The primary diagnoses of the children included generalized anxiety disorder $(n=12)$, social phobia $(n=8)$, specific phobia $(n=7)$ and separation anxiety disorder $(n=3)$. Twentythree children met criteria for more than one anxiety diagnosis, one for a mood disorder and four for externalizing disorders.

\section{Measures}

\section{Children's Anxiety Diagnosis}

The Anxiety Disorders Interview Schedule for Children, Version IV [ADIS-C/P-IV; 41] was used to determine the diagnostic status of all children based on parents' and children's reports of children's anxiety, mood, and externalizing problems. This structured interview initially probes for the main criteria of a diagnosis, which, when positively supported, is followed by a more detailed assessment of symptoms, level of fear, avoidance, and interference. We used an adapted procedure that allowed for the interviewing of both child and parent simultaneously [42], with questions first addressed to the child and afterwards to the parents. Also, intensity of fear and avoidance and interference probe questions were administrated separately to parents and children in order to avoid contamination between informants. A diagnosis was attributed when both parent and child agreed in at least one anxiety disorder with a correspondent significant clinical severity rating $(\geq 4)$ [see 40] or clinical judgment, based on further questioning if there were discrepancies between informants.

\section{Parental Behavior and Strategies}

Interview "Anxious to know" is a semi-structured interview especially constructed for our research project. This interview aims to analyze parent's cognitions, emotions and behaviors related to their child's anxiety. The interview comprised 11 groups of open-ended questions and was administrated individually. For the current study, we selected and analyzed only the two specific questions that addressed parents' perceptions about their practices and strategies to cope with their child's anxiety: "How do you normally act when your child is anxious/worried/nervous?" and "Which strategies do you use most frequently or in a more consistent way in these situations?"

Observations Two behavioral tasks were used in our study to analyze parental behavior. Each child participated in four observations (father/mother x speech/black boxes). The order of the tasks and the order of the parents' participation were previously counterbalanced and randomized. Both tasks were based and adapted from prior literature [e.g., 43] and intended to evaluate two broad types of anxiety. The first task_- "Let's make a speech" intended to elicit mild levels of social/performance anxiety in the child. Parents and children received the following instructions: "This task requires you to prepare a speech with the help of your parents about the importance of healthy eating (random general topic). Imagine that you were chosen to make an advertisement to be presented to all your schoolmates about this relevant issue. That speech will be filmed. Your mother will be helping you for the first $3 \mathrm{~min}$. Then your father will do the same. A clock will show you how much time you have left. After the preparation, you'll have to deliver the speech by yourself in front of the camera. Notice that you cant read it from any paper". Parents were in the room during the speech. The second task - "Blinded discovery"- was designed to induce anxiety associated to physical threat. Instructions were: "Now you have to discover what is inside these four black boxes. You have to introduce your hand into each box, without opening it or seeing what is inside. To pass this test, you can only fail once. This turn, your father will be the first to help you figure out what is inside boxes 1 and 2 . Then, your mother will do the same with boxes 3 and 4. After you finish, I will return into the room and count your successes and errors". In both tasks parents were instructed to help if, when and how they wished. The experimenter was not present during the task's completion.

\section{Procedure}

The present research was approved by the National Data Protection Commission, the General Administration for Innovation and Curriculum Development from the Portuguese Ministry of Education, and the Ethics Committee of the Faculty of Psychology of the University of Lisbon. 
The recruitment of children followed a multi-screening procedure. First, an initial sample of 987 children from 12 public schools completed a screening questionnaire assessing children's anxiety symptomatology [SCARED-R; 44]. A total of 51 families were excluded during this process for several reasons: (a) parents did not authorize the team to contact them in advance $(n=31)$; (b) parents were impossible to contact or unavailable at the moment of data collection $(n=18)$; (c) parents and/or child refused to participate $(n=6)$; and (d) the child lived in an institution $(n=1)$. Subsequently, 67 children and their parents, randomly selected from a subsample of 136 children that scored above the 85 th percentile in the total scale, were invited to the second phase of the study. The ADIS-C/P-IV were first conjointly administered to the child and the parents and subsequently parents were interviewed individually with "Anxious to know", as described above. Children who had other main diagnoses $(n=5)$ or sub-clinical symptoms of anxiety $(n=4)$ were excluded from the study. One mother was also excluded because she had not recognized the negative impact of the anxiety disorder on her child's functioning. After the realization of the interviews, families were invited to participate in the observations. A total of 30 children with a main diagnosis of anxiety disorder and both their parents were randomized and recruited to participate in the two tasks. Although all parents $(n=60)$ participated in the observed interactions, the present sample only includes those who had been previously interviewed with Anxious to know $(n=42)$. For that reason, some children had both their parents participating in the study $(n=13)$, while others only had one of their parents participating $(n=27)$. Interviews and observations occurred in the schools or in community sites convenient for the families and were conducted by the first author.

\section{Data Analysis}

\section{Qualitative Analysis}

The interviews were audio recorded. The qualitative analysis of parents' verbalizations followed several phases: (1) interviews were transcribed and entered into NVivo10 software for analysis; (2) verbalization excerpts were labeled to identify parents' recurring strategies and behaviors to deal with the child's anxiety; (3) a thematic framework approach was used "to classify and organize data according to key themes, concepts and emergent categories" [45, p. 262]; and (4) the synthesized data were organized into final theoretically meaningful categories (see Table 1). Then, the final categories were formulated, based on literature about parenting styles [e.g., 8] and about specific parental behaviors previously associated with anxiety in childhood [e.g., 46, 47]. A total of 10 parental strategies were identified. All transcriptions were analyzed by two different clinical psychologists experienced in conducting clinical interviews, which had received intensive training and participated in systematic discussions on the codification of interview excerpts. The percentage of the inter-rater agreement between coders was $90 \%$. Kappas from individual categories ranged from .82 to 1.00 .

\section{Quantitative Data}

The observations were video-taped. During the codification process, two independent coders, blind to the child's problems, identified children's verbal and non-verbal manifestations of anxiety. Prior to analysis, to guarantee the tasks' ecological validity, we confirmed that every child expressed anxious behavior in observed interactions and that parental strategies were applied in a mild stressful context for the child. No child needed to be excluded. Several procedures were considered for the analysis of observations: (1) codes were identified to describe parents' specific behaviors (e.g., specific suggestions, interruptions, criticism); (2) these detailed codes were organized into larger categories meant to fit the same theoretical framework as the data from the interviews; and (3) two graduate observers coded $20 \%$ of randomized videotapes to verify the inter-observer agreement. Prior to codification, feedback was given to the observers during the training process to improve their accuracy. Training lasted until they reached an acceptable agreement. Inter-observer agreement was computed with Cohen's Kappa coefficients, using the program General Sequential Querier (GSEQ, Version 5.0; Georgia State University, Atlanta, GA, USA). Only the codes that achieved $80 \%$ of agreement [corresponding to a minimum kappa of .60; see [48] were used in the subsequent analysis. The total inter-rater agreement kappa coefficient was .81. Kappas for individual codes ranged from .65 to 1.00 .

We started by analyzing which strategies were reported in the interviews and observed during the interactions. The three most frequent strategies were retained for each context. The strategies were then dichotomized according to their presence or absence in each interview and in each observation and entered into the database. 2 (interview/ observation) $\times 2$ (presence/absence of the strategy) crosstabulation tables were drawn to compare the proportion of parents who reported and used each strategy. Afterwards, Chi square tests were performed in order to explore the existence of differences in each reported and observed strategy, according to the child's and parent's gender. Finally, for each parental strategy, non-parametric tests for repeated samples (McNemar's test) were used to examine the discrepancies between the strategies that parents 
Table 1 Description of parental strategies used to deal with children's anxiety with examples from the interviews and observed behaviors

\begin{tabular}{lll}
\hline Parental strategies & Excerpts from interviews & Examples of behaviors
\end{tabular}

1. Overinvolvement

Behaviors that express overprotection, overcontrol, psychological control and intrusiveness

Includes invasive/unsolicited emotional and/or practical support and commands or attempts to take over, used by the parents to direct the child's behavior in a verbal or physical way

\section{Reassurance}

Parents try to restore their child's confidence by conveying messages which transmit security in an inappropriate or unrealistic way. They satisfy the child́s need for reassurance or assure them that negative outcomes will not happen

\section{Reinforcement of avoidance and dependence}

Verbal and non-verbal expressions conveying or reinforcing avoidance or dependency

\section{Anxious behavior}

Verbal and non-verbal expressions and reinforcement of fear, apprehension, worry catastrophizing and anxiety. Includes perfectionistic and high standards statements

\section{Helplessness}

Expressions of inability to help and direct the child, of lack of control over the situation; pessimism

\section{Passivity}

Withdrawal and inhibition, unresponsiveness to the child's behavior and communication

\section{Negativity}

Criticism, negative or aggressive behaviors and verbalizations, expressions of negative affect, blaming the child, minimizing the child's feelings

\section{Task resolution approach}

Development and planning of strategies organized to solve the task

\section{Emotional support}

Verbal or behavioral expressions of empathy and affection, encouraging the child to express his/her emotions and thoughts, using positive reinforcement or praising the child

\section{Encouragement of bravery}

Encouraging bravery and an approach to fearful situations

Includes parental modelling or instructions to use approach behaviors
"I had to choose her school myself, even though I knew that she disliked that decision" (Mother, 12 year- old girl)

"He asked me if there was any chance of a tsunami or an earthquake occurring here. I replied: 'Of course not!' But it is not true. It happened once" (Father, 9 year-old boy)

"She needs me to stay next to the bus until it goes away. She needs me to keep saying goodbye all the time. If I leave, she will just panic" (Mother, 11 year-old girl)

(When the child was insecure about her homework) "I told her that she needed to study harder in order to have a good result in the exam" (Father, 9 year-old girl)

"There are not many things we can do to help her with her fears. I don't think we can do anything as parents" (Father, 11 year-old girl)

"I didńt do anything regarding those social problems. Those will be over when she grows up" (Mother, 10 year-old girl)

"I was not able to get him to stop crying. I could not stand it anymore! I had to slap him" (Mother, 9 year-old boy)

"We advised her on possible ways to solve her problems. She was able to get other perspectives on how to cope with them" (Mother, 12 year-old girl)

"I tell him that it's all right to be scared. I explain that he isńt the only one who is scared. I have my own fears but this cańt be an excuse to give up" (Mother, 10 year-old boy)

"I have to tell her: 'Let's see the dog closer and play with him. Stay still and wait for him to come over and smell you" (Mother, 12 year-old boy)
Parents tell the child exactly what she should say during the speech or decide for her what is inside the boxes

Verbalizations such as "Don't worry. I'm sure there is no animal inside the boxes" or "Calm down! Everything will be fine"

Expressions such as "You do not have to put your hand in there if you dońt want to"

Verbalizations such as "God, we are running out of time", "Check all the boxes again to be sure" or "I hope they like your speech"

Verbalizations such as "I cannot help you" or "I have no clue about what you must say in the speech"

Parents stay physically distant, silent, give minimal responses to the child, or just wait for the child to do something

Negative expressions such as "you are being too lazy" or "you will never do it!"

Parents suggest ideas on how to explore the boxes' content ("try to see if it's short or long") or give suggestions ("Maybe it's a mouse?")

Parent smile, praise, compliment or show affection towards the child through gestures

Verbalizations such as "Go on to the next box, you are doing fine" and "dońt give up now, you're almost finished" 
reported in the interview and the strategies observed during the interactions. We defined the level of significance at $p<.05$. Analyses were performed using SPSS 22.0 (SPSS, Chicago, IL, USA).

\section{Results}

\section{Strategies Reported by Parents}

Most frequent parental strategies are described in Table 1 with respective examples from interviews and observed behaviors.

Task resolution approach and encouragement of bravery were the strategies that parents reported using most regularly (Table 2). Task resolution approach was mentioned by 22 parents and is characterized by several behaviors focused on solving the situation and promoting the child's ability to solve the problem including: (a) structured and instrumental actions ["I told him that when he is afraid of the dark, he just has to go to the hall and switch the light on instead of asking for my help or fleeing"; father, 9 year-old boy]; (b) planning ["I advised her: Today you wońt feel any better. I will make tea for both of us and we will rest. Tomorrow I will wake you up early and you will do a quick revision for the test. I'll help you if you want"; mother, 10 year-old girl]; (c) developing positive expectations ["I explained to her where we were going, what was going to happen during the vaccination and that she would meet that kind nurse from the last time"; mother of a 9 year-old girl]; and (d) information seeking ["We instructed her to ask her teacher to give some feedback about her actual performance, to give her some guidelines"; father, 9 year-old girl].
Encouragement of bravery, also mentioned by 22 parents, is a strategy that includes actions to encourage or reinforce the child's exposition to anxiogenic situations. Sometimes the child was encouraged to gradually approach the feared stimuli ["First I used to sleep with him. Then I told him that he was growing up and that he had to stay in his own bed. At that time, he always had a dim light on after we left the room. Nowadays, he doesńt need the light anymore"; father, 9 year-old boy]. At times, parents encourage the child in a more immersive way ["He wanted to leave the park as soon as he saw the two doggies. I showed him that they were very small and kind. We just went there and I convinced him to get close to them"; mother, 9 year-old boy]. Some parents also reported that they modeled exposure or brave behaviors in order to positively influence their children ["I encouraged her to go talk to that actor. We got closer to him and then I went and asked him for an autograph. She could not do it, but I tried it myself to show her how to do it"; mother, 11 year-old girl]. A few parents reported using some form of deception to lead the child to approach feared situations. In those cases, the children did not realize they were being exposed ["I told him to keep playing in his grandma's house. We explained we had to go home because we needed to get up early in the morning but he could stay there playing with his grandma"; father, 9 year-old boy].

The following most reported strategy was reassurance $(n=22)$. Most parents referred to using this strategy alone, without any other complementary strategy ["I kept telling her not to worry. That I was going out but I would return (...) I had to explain various times that the plane was not going to crash"; father, 10 year-old girl]. This strategy was reported to be used frequently in response to the child's request for reassurance [e.g., "I had to call my sister. It was
Table 2 Frequencies, percentages and differences between parents that report the use of these coping strategies and parents who applied them in interactions with the child

\begin{tabular}{|c|c|c|c|c|c|}
\hline \multirow[t]{2}{*}{ Parental coping strategies } & \multicolumn{2}{|c|}{ Reported in interviews } & \multicolumn{2}{|c|}{ Observed in interactions } & \multirow[t]{2}{*}{$p$ value } \\
\hline & $\mathrm{N}$ & $\%$ & $\mathrm{n}$ & $\%$ & \\
\hline Task resolution approach & 22 & 52.4 & 32 & 76.2 & .064 \\
\hline Encouragement of bravery & 22 & 52.4 & 25 & 59.6 & 678 \\
\hline Reassurance & 20 & 47.6 & 10 & 23.8 & $.031 *$ \\
\hline Reinforcement of avoidance/dependence & 18 & 42.9 & 1 & 2.4 & $.000 * *$ \\
\hline Emotional support & 15 & 35.7 & 11 & 26.2 & .523 \\
\hline Negativity & 15 & 35.7 & 19 & 45.2 & .503 \\
\hline Overinvolvement & 13 & 31.0 & 35 & 83.3 & $.000 * *$ \\
\hline Helplessness & 7 & 16.7 & 7 & 16.7 & 1 \\
\hline Anxious behavior & 5 & 11.9 & 34 & 81.0 & $.000 * *$ \\
\hline Passivity & 3 & 7.1 & 8 & 19.0 & .227 \\
\hline
\end{tabular}

Paired differences in the agreement between strategies reported and observed were obtained by McNemar's test

$* p<.05 ; * * p<.001$ 
the only way to calm down my daughter and reassure her that her aunt was ok"; father, 10 year-old girl].

Eighteen parents mentioned reinforcement of avoidance/ dependence. Some parents admitted that they felt partially responsible for the lack of opportunities available for their child to face difficult situations ["I tell him to stay away from dogs"; mother, 11-year-old girl].

Emotional support was reported by fifteen parents. Parents mentioned a number of practices conveying empathy, emotional expression, encouragement to talk about his/her feelings. All these behaviors translate into the intention to express warmth, acceptance and understanding about the child's experience and emotions ["When she is really out of control, I give her a hug and tell her that it's alright to cry. After a while, I stand by her and ask her to tell me whats going on"; mother, 10 year-old girl].

Negative strategies were also mentioned by a similar number of parents. Parents tended to justify the use of these strategies with their lack of empathy for the child's fears and worries or because they considered that the child was overreacting ["I told him: Do you need to fuss about all this?! Please J., you are overdoing it!"; mother, 9 year-old boy]. Some parents justified these behaviors as a consequence of their own feelings of tiredness, impatience and frustration when facing the child's distress ["It was $10 \mathrm{pm}$ and she kept asking me if she was prepared for the test. I told her that I did not want to know about it. I scolded her and told her to simply forget about it. I recognize that I was rude"; mother, 9 year-old girl].

Overinvolvement was mentioned by thirteen parents. Many of these behaviors reflect parents' intention to prevent their child from experiencing any harm, pain, unhappiness, rejection, failure or disappointment. In most cases, these strategies involved some restrictions to the child's autonomy, decreasing his/her opportunity to face any difficulties ["I have to dress her and make everything for her before she goes to school. Now, she is starting to do some things by herself but... Honestly, I don't allow her to be more independent"; mother, 10 year-old girl]. Some parents recognized overinvolvement and intrusive practices as exaggerated or even inadequate and justified their overinvolvement with their own worries and anxiety ["I shouldn't be so protective and should let her walk to school by herself. But, she is so absent-minded, I am afraid that a car will hit her"; mother, 10 year-old girl].

Seven parents mentioned helplessness reactions, expressing low self-efficacy on handling the child's distress or their inability to deal with the problem itself ["I say to him, forget about it but after a while I also start crying"; mother, 10 year-old boy].

Five parents mentioned that they engaged in anxious behavior as a response to the child's anxious behaviors ["I also got nervous with that exam"; father, 10 year-old girl].
Some parents justified the use of this strategy with the child's vulnerability, whereas others referred to their own empathy with the child's fears ["I am not a good example for him. I also get scared during storms"; mother, 11 yearold boy].

Some parents reported a passive reaction to their child's anxiety (i.e., doing nothing or not reacting to the child's anxiety), either because they do not recognize the child is anxious ["I do not recognize if he is anxious or not. Most of the time he also does not talk about it"; father, 9 yearold boy], or because they do not perceive the need to manage the child's distress ["I did nothing. I did not insist that he come with us to the beach. During last week, I tried to talk about the subject but it was pointless, so I didn't say anything else"; mother, 10 year-old boy]. Two parents considered the child's anxiety as a temporary developmental phase and, as a consequence, decided not to act on it ["I did nothing. I think he will learn to deal with his fears. Everyone has fears, right? At his age it is normal not to know how to handle them"].

No differences were found in the frequencies of parents who reported using each of these strategies, in relation to the child's gender [Overinvolvement: $\chi^{2}(1)=1.00$; $p=.32 /$ Reassurance: $\chi^{2}(1)=1.53 ; p=.22 /$ Anxious behavior: $\chi^{2}(1)=.23 ; p=.63 /$ Passivity: $\chi^{2}(1)=.36$; $p=.55 /$ Helplessness: $\chi^{2}(1)=.17 ; p=.68 /$ Negativity: $\chi^{2}$ $(1)=.10 ; p=.75 /$ Emotional support: $\chi^{2} \quad(1)=2.59$; $p=.11$ /Task resolution approach: $\chi^{2}(1)=.82 ; p=.54$ ] and in relation to the parents gender [Overinvolvement: $\chi^{2}$ $(1)=.19 ; p=.89 /$ Reassurance: $\chi^{2}(1)=.12 ; p=.73 /$ Reinforcement of avoidance/dependence: $\chi^{2}(1)=.85$; $p=.36 /$ Anxious behavior: $\chi^{2}(1)=1.19 ; p=.28 /$ Passivity: $\chi^{2}(1)=.24 ; p=.62 /$ Helplessness: $\chi^{2}(1)=2.33$; $p=.13 /$ Negativity: $\chi^{2}(1)=.14 ; p=.71 /$ Emotional support: $\chi^{2}(1)=.47 ; p=.49 /$ Task resolution approach: $\chi^{2}$ $(1)=.12 ; p=.73]$. Chi square tests could not be computed in two strategies relating to the child's gender because of the low proportion of parents who referred to using these strategies (i.e., reinforcement of avoidance/ dependence and encouragement of bravery).

\section{Strategies Observed in Dyadic Interactions}

As shown in Table 2, overinvolvement, expressed through intrusive, overprotective and invasive behaviors, was the most frequent strategy observed during the two structured tasks $(n=35)$. Manifestation of anxious behavior was also shown by the majority of parents $(n=34)$. Task resolution approach was used by thirty-two parents and includes attempts to plan the activity or to give specific suggestions oriented toward the problems' resolution. Twenty-five parents helped their child to approach fearful or distressful situations, mostly through verbalizations of encouragement 
of bravery. Nineteen parents used strategies centered on negativity, resorting to criticism and devaluating the child's feelings. Emotional support was used by eleven parents, mainly with expressions of care and affection toward the child. Ten parents used reassurance to respond to the children's anxiety and to calm them down. Eight parents revealed passivity (i.e., they did not react to the child's anxious behaviors), while seven manifested helplessness. Finally, only one parent reinforced the child's avoidancel dependence when she gave up trying to complete the task.

Chi square tests found no significant difference in the proportion of parents that applied the above strategies during parent-child interactions, in relation to the child's gender [Overinvolvement: $\chi^{2}(1)=.53 ; p=.47 /$ Task resolution approach: $\chi^{2}(1)=.17 ; p=.68 /$ Emotional support: $\chi^{2}(1)=$ $.12 ; p=.73 /$ Encouragement of bravery: $\chi^{2}(1)=2.47$; $p=.12 /$ Negativity: $\chi^{2}(1)=.87 ; p=.35 /$ Helplessness: $\chi^{2}$ $(1)=.17 ; p=.68 /$ Reassurance: $\chi^{2}(1)=2.10 ; p=.15 /$ Anxious behavior: $\chi^{2}(1)=2.47 ; p=.12 /$ Reinforcement of avoidance/dependence: $\left.\chi^{2}(1)=1.02 ; p=.31\right]$ and in relation to the parent's gender [Overinvolvement: $\chi^{2}(1)=.19$; $p=89 /$ Task resolution approach: $\chi^{2}(1)=.12 ; p=.73 /$ Emotional support: $\chi^{2}(1)=.47 ; p=.49 /$ Encouragement of bravery: $\chi^{2}(1)=.19 ; p=.66 /$ Negativity: $\chi^{2}(1)=.14$; $p=.71 /$ Helplessness: $\chi^{2}(1)=2.33 ; p=.13 /$ Passivity: $\chi^{2}$ $(1)=.23 ; p=63 /$ Reassurance: $\chi^{2}(1)=.12 ; p=.73 /$ Anxious behavior: $\chi^{2}(1)=1.19 ; p=.28 /$ Reinforcement of avoidance/dependence: $\left.\chi^{2}(1)=.85 ; p=.36\right]$.

\section{Discrepancies Between Reported and Observed Coping Strategies}

The results concerning the number of parents who in the interview reported using the strategies and those who applied them during interactions are presented in Table 2. McNemar's tests showed no significant differences between the majority of strategies in these two contexts. However, important exceptions were found. Significantly more parents adopted overinvolvement and anxious behavior during observed interactions than parents who reported their consistent use in everyday situations. In the opposite direction, significantly less parents used reassurance and reinforcement in their interactions than would be expected by their reports.

\section{Discussion}

It has been consistently demonstrated that parents play an important role in the development and maintenance of child anxiety. There is strong evidence for the efficacy of individual cognitive-behavioral therapy (ICBT) in reducing anxiety problems in children [for a review see 49]. Although family-focused interventions combined with ICBT have not proved to increase the treatment's efficacy in a significant way [e.g., 50], there is evidence of the advantages of including a family component in the intervention, such as less family disruption, higher parental self-efficacy to deal with the child's behaviors or better parental management of their own anxiety [51]. The present study intended to contribute to this domain by examining parental strategies both self-reported and observed in interactions between parents (fathers and mothers) and their anxious child, using a mixedmethod approach. In general, findings indicated the existence of similarities and discrepancies between strategies identified by these different methodologies.

Ten major parental strategies to deal with the child's anxiety were identified in our findings. Overall, it is possible to divide these strategies into three main groups. A first group of strategies-overinvolvement, reinforcement of avoidance/dependence and reassurance-reflect parent's maladaptive actions to regulate the child's distress in the short-term, thus contributing to reinforce their child's anxiety in the long term. A second group of strategies-anxious behavior, helplessness, negativity and passivity-reflect parent's emotional reactions to the child's distress [52]. In a third group of strategies, parents engage in adaptive actions directed at regulating the child's anxiety and helping him/her cope with the stressful situation, including emotional support, encouragement of bravery and task resolution approach. It is hypothesized that the first two types of strategies may be associated with parent's own negative emotions and poor emotional self-regulation.

In line with previous research, we found no differences between both reported and observed strategies, concerning the child's and parent's gender [8, 9, 53, 54]. This finding indicates that both mothers and fathers referred to and used similar strategies to deal with their child's anxiety, confirming the equally important influence of the paternal and maternal role in the development and maintenance of childhood anxiety [39].

\section{Strategies Reported by Parents}

When parents were asked which strategies they use most regularly and/or consistently, the majority of parents reported adaptive strategies. This may suggest that parents recognize which strategies are more appropriate to help the child cope with negative affect. As was the case in findings reported by Hiebert-Murphy et al. [34] where the majority of parents reported using effective strategies, such as emotional support, which is in accordance to what is recommended and promoted in intervention programs [6].

However, less positive strategies were also mentioned. Reassurance, for instance, was reported by a considerable 
number of parents. This strategy is considered a simple and rapid way of calming down the child, although it might contribute to maintain and intensify the child's anxiety over time. Children with generalized anxiety disorder, for example, often seek reassurance from their parents in an attempt to be absolutely sure that everything they are doing is okay or that nothing bad will happen and parents often comply with these demands. However, in the long run, this strategy may reinforce children's anxiety and their dependence on parents, who they perceive as having the necessary skills to regulate their negative emotional states. Other strategies aimed at immediately reducing the child's distress (i.e., reinforcement of avoidance/dependence and overinvolvement) were also mentioned by several parents.

The less reported strategies reflect parent's own emotional dysregulation (helplessness, anxious behavior and passivity). These strategies represent a reactive and less regulated way of facing the child's distress rather than more voluntary and reflexive strategies. These characteristics may explain that parents are less aware of their usage and as such report them less. However, it is also probable that this result might be associated with the way we prompted parents' descriptions of strategies (i.e., we asked about what they usually do and which strategies they use more frequently). Parents might have mentioned only the more voluntary and planned strategies they use, rather than their more automatic reactions to the child's behavior. This finding can also be linked with social desirability answers, as parents may have difficulty in admitting their lack of intentional strategies or their sense of helplessness when they face their child's distress.

\section{Observed Parental Strategies}

During the observation of parent-child interactions, the strategies most used by parents were overinvolvement and anxious behavior. This result confirms previous observational studies showing that parents of anxious children behave in an overinvolved and intrusive manner [e.g., 9]. Surprisingly, the reinforcement of avoidance/dependency was the least used strategy. In our study, parents were more prone to influence the child through modeling of anxious behavior than through reinforcement of avoidant/dependent responses. This may be related to the type of tasks used and the clear instruction forbidding parents to interfere in the speech delivery and in the direct exploration of the black boxes.

Adaptive strategies such task resolution approach and encouragement were frequently used, confirming that many parents are able to respond adequately to their child's distress [34]. Similarly to what parents reported in the interviews, passivity and helplessness were less used, suggesting that most parents are able to help their child cope with anxiety-provoking situations and do not often revert to withdrawal.

\section{Discrepancies and Similarities Between Reported and Observed Parental Strategies}

For most strategies, the percentage was similar in the interviews and the observations, revealing that parents are mostly consistent and aware of their behaviors when their child is anxious. Nevertheless, discrepancies were found concerning four strategies. Overinvolvement and anxious behavior were significantly more used in the interactions than reported by parents. On the contrary, reassurance and reinforcement of avoidance/dependency were not observed as often in the interactions as would be expected from the parents' descriptions. These discrepancies are probably due to various factors. Firstly, parents may be less aware of their use of certain strategies, such as overinvolvement or anxious behavior, as these may be difficult to grasp by the parents or are applied as an automatic reaction to the child's distress. Secondly, the way parents respond to their child's distress usually depends on the context. It is possible that the two tasks observed in this study might not have elicited sufficient levels of intense fear or worry, or the need for reassurance. As many parents mentioned, this strategy is mostly used in response to their children's frequent worries related to their daily routines (e.g., school, health of relatives, divorce). Reinforcement of avoidance/dependency would probably occur more frequently if the tasks had elicited more intense anxious and avoidant responses in their children or if parents perceived them as more threatening. Lastly, parents' emotional state may have influenced the way they reported and recognized the use of certain strategies. It is plausible that during the interviews, parents do not vividly recall the way they feel in the actual daily situations or simply limit their responses to planned strategies thus not including their emotional reactions. However, during the interactions, parents may have felt anxious both in response to the child's anxious reactions and to their own discomfort [e.g. 55, 56].

\section{Limitations}

There are some important limitations in the current study. We compared strategies used in distinct contexts (real situations vs laboratorial) and in different moments (past situations vs present situations). The small sample size may have limited the power of the discrepancies identified and prevented the application of a more complex statistical analysis. Additionally, parental anxiety status was not assessed, making the interpretation of results difficult. In the future it would be relevant to explore if each of these strategies are used mainly by non-anxious or anxious parents or indistinctively by any parents. 


\section{Summary}

Despite an overall consistency between self-reported and observed parental strategies, some important discrepancies were found. Particularly, the use of overinvolvement and anxious behavior may indicate that parents are less aware of their usage or that they did not identify them as planned strategies. Future studies should analyze the strategies parents use intentionally and their emotional reactions, in order to capture these different aspects of parental behavior [57]. Parents' distress and their inability to regulate their own anxiety may also have contributed to the adoption of strategies based on overinvolvement and anxious behavior in the observed situations. Despite this result, most parents used adaptive strategies, indicating that parents recognize and apply useful strategies to help children face stressful situations.

The current study has significant strengths and practical implications. Our multi-method (qualitative, observational and quantitative analysis) and multi-informants (fathers/mothers and independent raters) approach increased our understanding of the strategies and behaviors parents use to respond to their child's distress, based on their own perspectives (ecological validity), which might be a useful practice to replicate in research and in clinical settings. Self-monitoring measures to assess parents' emotional reactions and intentional strategies in real contexts may be a useful tool to increase parental self-awareness and modify their use of maladaptive strategies. Using complementary methods during clinical evaluation and intervention might also give invaluable information to clinicians about how parents cope with childhood anxiety (e.g., self-report measures, observation of family interactions) and also as a target during the therapeutic process with parents (e.g., video feedback). Lastly, it might be important to further identify parents' difficulties in implementing these strategies in natural contexts and solve those barriers in order to guarantee more effective interventions with anxious children and their families.

Acknowledgments The authors acknowledge Teresa Tupholme for her assistance in the English text revision and all the families who participated in the study.

Funding This work was funded by Fundação para a Ciência e Tecnologia (Grant Number SFRH/7737/2011 awarded to A. Beato and PTDC/PSI-PCL/122007/2010 awarded to A. I. Pereira).

\section{Compliance with Ethical Standards}

Conflict of interest The authors declare that they have no conflict of interest.

Ethical Approval All procedures performed in studies involving human participants were in accordance with the ethical standards of the institutional and/or national research committee and with the 1964
Helsinki declaration and its later amendments or comparable ethical standards.

Informed Consent Informed consent was obtained from all individual participants included in the study.

\section{References}

1. Schreier A, Wittchen H, Höfler M, Lieb R (2008) Anxiety disorders in mothers and their children: results from a prospectivelongitudinal community study. Br J Psychiatry 192:308-309

2. Gregory A, Eley T (2007) Genetic influences on anxiety in children: what we've learned and where we're heading. Clin Child Fam Psychol Rev 10:199-212

3. Bögels S, Brechman-Toussaint M (2006) Family issues in child anxiety: attachment, family functioning, parental rearing and beliefs. Clin Psychol Rev 26:834-856

4. Ginsburg G, Siqueland L, Masia-Warner C, Hedtke K (2004) Anxiety disorders in children: family matters. Cogn Behav Pract 11:28-43

5. Chorpita B, Brown T, Barlow D (1998) Perceived control as a mediator of family environment in etiological models of childhood anxiety. Behav Ther 29:457-476

6. Ginsburg G, Schlossberg M (2002) Family-based treatment of childhood anxiety disorders. Int Rev Psychiatry 14:143-154

7. Rapee R (2001) The development of generalized anxiety. In: Vasey M, Dadds M (eds) The developmental psychopathology of anxiety. Oxford University Press, Oxford, pp 481-503

8. McLeod B, Wood J, Weisz J (2007) Examining the association between parenting and childhood anxiety: a meta-analysis. Clin Psychol Rev 27:155-172

9. van der Bruggen C, Stams G, Bögels S (2008) Research review: the relation between child and parent anxiety and parental control: a meta-analytic review. J Child Psychol Psychiatry 49:1257-1269

10. Verhoeven M, Bögels S, van der Bruggen C (2012) Unique roles of mothering and fathering in child anxiety: moderation by child's age and gender. J Child Fam Stud 21:331-343

11. Darling N, Steinberg L (1993) Parenting style as context: an integrative model. Psychol Bull 113:487-496

12. Karreman A, van Tuijl C, van Aken M, Decović M (2006) Parenting and self-regulation in preschoolers: a meta-analysis. Infant Child Dev 15:561-579

13. Silk J, Morris A, Kanaya T, Steinberg L (2003) Psychological control and autonomy granting: opposite ends of a continuum or distinct constructs? J Res Adolesc 13:113-128

14. Fisak J, Grills-Taquechel A (2007) Parental modeling, reinforcement, and information transfer: risk factors in the development of child anxiety? Clin Child Fam Psychol Rev 10:213-231

15. Muris P, Steerneman P, Merckelbach H, Meesters C (1996) The role of parental fearfulness and modeling in children's fear. Behav Res Ther 34:265-268

16. Field A, Lawson J, Banerjee R (2008) The verbal threat information pathway to fear in children: the longitudinal effects on fear cognitions and the immediate effects on avoidance behavior. J Abnorm Psychol 117:214-224

17. Silk J, Sheeber L, Tan P, Ladouceur C, Forbes E, McMakin D et al (2013) You can do it!: the role of parental encouragement of bravery in child anxiety treatment. J Anxiety Disord 27:439-446

18. Cobham V, Dadds M, Spence S (1999) Anxious children and their families: what do they expect? J Clin Child Psychol 28:220-231

19. Kortlander E, Kendall P, Panichelli-Mindel S (1997) Maternal expectations and attributions about coping in anxious children. J Anxiety Disord 11:297-315 
20. Creswell C, Willetts L, Murray L, Singhal M, Cooper P (2008) Treatment of child anxiety: an exploratory study of the role of maternal anxiety and behaviours in treatment outcome. Clin Psychol Psychother 15:38-44

21. Whaley S, Pinto A, Sigman M (1999) Characterizing interactions between anxious mothers and their children. J Consult Clin Psychol 67:826-836

22. Chorpita B, Barlow D (1998) The development of anxiety: the role of control in the early environment. Psychol Bull 124:3-21

23. Rubin K, Burgess K (2001) Social withdrawal and anxiety. In: Vasey MW, Dadds MR (eds) The developmental psychopathology of anxiety. Oxford University Press, Oxford, pp 407-434

24. Ginsburg G, Drake K, Tein J, Teetsel R, Riddle M (2015) Preventing onset of anxiety disorders in offspring of anxious parents: a randomized controlled trial of a family-based intervention. Am J Psychiatry 172:1207-1214

25. Herman M, McHale S (1993) Coping with parental negativity: links with parental warmth and child adjustment. J Appl Dev Psychol 14:121-136

26. Kliewer W, Fearnow M, Miller P (1996) Coping socialization in middle childhood: tests of maternal and paternal influences. Child Dev 67:2339-2357

27. Skinner E, Wellborn J (1994) Coping during childhood and adolescence: a motivational perspective. In: Featherman D, Lerner R, Perlmutter M (eds) Life-span development and behavior. Erlbaum, NJ, pp 91-133

28. Markstrom C, Marshall S, Tryon R (2000) Resiliency, social support, and coping in rural low-income appalachian adolescents from two racial groups. J Adolesc 23:693-703

29. Wills T, Cleary S (1996) How are social support effects mediated? A test with parental support and adolescent substance use. J Soc Personal Psychol 71:937-952

30. Sandler I, Wolchik S, MacKinnon D, Ayers T, Roosa M (1997). Developing linkages between theory and intervention in stress and coping processes. In: Handbook of children's coping. Springer, US, pp 3-40

31. Bean R, Barber B, Crane D (2006) Parental support, behavioral control, and psychological control among African American youth the relationships to academic grades, delinquency, and depression. J Fam Issues 27:1335-1355

32. Langrock A, Compas B, Keller G, Merchant M, Copeland M (2002) Coping with the stress of parental depression: parents' reports of children's coping, emotional, and behavioral problems. J Clin Child Adolesc Psychol 31:312-324

33. Compas BE (1998) An agenda for coping research and theory: basic and applied developmental issues. Int $\mathbf{J}$ Behav Dev 22:231-237

34. Hiebert-Murphy D, Williams E, Mills R, Walker J, Feldgaier S, Warren $M$ et al (2011) Listening to parents: the challenges of parenting kindergarten-aged children who are anxious. Clin Child Psychol Psychiatry 17:384-399

35. Pereira A, Muris P, Barros L, Goes R, Marques T, Russo V (2015) Agreement and discrepancy between mother and child in the evaluation of children's anxiety symptoms and anxiety life interference. Eur Child Adolesc Psychiatry 24:327-333

36. Drake K, Ginsburg G (2011) Parenting practices of anxious and nonanxious mothers: a multi-method, multi-informant approach. Child Fam Behav Ther 33:299-321

37. Foley D, Rutter M, Pickles A, Angold A, Maes H, Silberg J et al (2004) Informant disagreement for separation anxiety disorder. J Am Acad Child Adolesc Psychiatry 43:452-460

38. De Los Reys A, Kazdin A (2005) Informant discrepancies in the assessment of childhood psychopathology: a critical review, theoretical framework, and recommendations for further study. Psychol Bull 131:483-509

39. Bögels S, Phares V (2008) Fathers' role in the etiology, prevention and treatment of child anxiety: a review and new model. Clin Psychol Rev 28:539-558

40. Bögels S, Perotti E (2010) Does father know best? A formal model of the paternal influence on childhood social anxiety. J Child Fam Stud 20:171-181

41. Silverman W, Albano A (1996) Anxiety disorders interview schedule for DSM-IV: parent interview schedule, vol 1. Oxford University Press, Oxford

42. Khanna M, Kendal P (2010) Computer-assisted cognitive behavioral therapy for child anxiety: results of a randomized clinical trial. J Consult Clin Psychol 78:737-745

43. Creswell C, Apetroaia A, Murray L, Cooper P (2013) Cognitive, affective, and behavioral characteristics of mothers with anxiety disorders in the context of child anxiety disorder. J Abnorm Child Psychol 122:26-38

44. Muris P, Merckelbach H, Schmidt H, Tierney S (1999) Disgust sensitivity, trait anxiety and anxiety disorders symptoms in normal children. Behav Res Ther 37:953-961

45. Ritchie J, Lewis J (2003) Qualitative research practice. A guide for social scientists. Sage, London

46. Ginsburg G, Grover R, Cord J, Ialongo N (2006) Observational measures of parenting in anxious and nonanxious mothers: does type of task matter? J Clin Child Adolesc Psychol 35:323-328

47. Sluis C, van Steensel F, Bögels S (2015) Parenting clinically anxious versus healthy control children aged 4-12 years. J Anxiety Disord 32:1-7

48. Yoder P, Symons F (2010) Observational measurement of behavior. Springer, NY

49. Silverman W, Berman S (2001) Psychosocial interventions for anxiety disorders in children: status and future directions. In: Silverman WK, Treffers PDA (eds) Anxiety disorders in children and adolescents: research, assessment and intervention. Cambridge University Press, Cambridge, pp 313-334

50. Bodden D, Bögels S, Nauta M, De Haan E, Ringrose J, Appelboom C et al (2008) Child versus family cognitive-behavioral therapy in clinically anxious youth: an efficacy and partial effectiveness study. J Am Acad Child Adolesc Psychiatry 47:1384-1394

51. Cobham V, Dadds M, Spence S (1998) The role of parental anxiety in the treatment of childhood anxiety. J Consult Clin Psychol 66:893-905

52. Barros L, Goes A, Pereira A (2015) Parental self-regulation, emotional regulation and temperament: implications for intervention. Estud Psicol 32:295-306

53. Barrett P, Fox T, Farrell L (2005) Parent-child interactions with anxious children and with their siblings: an observational study. Behav Change 22:220-235

54. Bögels S, Bamelis L, Bruggen C (2008) Parental rearing as a function of parent's own, partner's, and child's anxiety status: fathers make the difference. Cogn Emot 22:522-538

55. Adam E, Gunnar M, Tanaka A (2004) Adult attachment, parent emotion, and observed parenting behavior: mediator and moderator models. Child Dev 75:110-122

56. Turner S, Beidel D, Roberson-Nay R, Tervo K (2003) Parenting behaviors in parents with anxiety disorders. Behav Res Ther 41:541-554

57. Connor-Smith J, Compas B (2004) Coping as a moderator of relations between reactivity to interpersonal stress, health status, and internalizing problems. Cogn Ther Res 28:347-368 